\title{
Competitiveness and Yield Advantage of Carrot-Rosemary Intercropping over Solitary at Wondo Genet, Southern Ethiopia
}

\author{
AshenafiNigussie*, Muleta Gadissa, Nibret Tadesse \\ ${ }^{1}$ Ethiopia Institute of Agricultural Research, Wondo Genet Agriculture Research Center P.O.Box 198 \\ Shashemene Ethiopia
}

*Corresponding Authors: AshenafiNigussie, Ethiopia Institute of Agricultural Research, Wondo Genet Agriculture Research Center P.O.Box 198 Shashemene Ethiopia

\begin{abstract}
To investigate yield, the competitive and intercropping advantage of carrot-rosemary intercropping over solitary a field study was carried out at Wondo genet Agricultural Research Center during 2016-2017 and 2017-2018 cropping seasons under irrigated condition. The experiment comprised of six treatments: sole carrot, sole Rosemary and four carrot-rosemary intercropping with mix proportion: 100 carrot: 25 rosemary, 100 carrots: 50 rosemary, 100 carrots: 75 rosemary and 100 carrot: 100 rosemary, using randomized complete block design with three replications. Analysis of variance revealed that; intercropping of carrot with different population densities of rosemary significantly affected economic yield; the highest yield was obtained at mono-cropping than that of intercropped. Similarly; essential oil yield of rosemary significantly influenced by cropping system; the highest essential oil yield gained in sole planted than intercropped. The highest value of the land equivalent ratio (1.73), land equivalent coefficient (0.84) and relative crowding coefficient (31.17) obtained when carrot intercropped with rosemary at $100 \%$ population density. However, minimum actual yield loss and maximum intercropping advantage obtained in treatments where carrot intercropped with rosemary at $25 \%$ population density. Generally, these findings suggest that intercropping of carrot with rosemary at $100 \%$ population density enhanced yield advantage and Competitiveness as indicated by higher land equivalent ratio and relative crowding coefficient. Therefore, the inclusion of carrot with $100 \%$ a rosemary population density raised yield advantage and competitiveness over solely planted crop per unit area as indicated by higher LER and relative crowding coefficient.
\end{abstract}

Keywords: Competitiveness, Intercropping, Solitary, Yield Advantage

\section{INTRODUCTION}

The demand for medicinal and aromatic plants is increasing gradually at national as well as international markets. Therefore, intercropping of aromatic and medicinal plants should be advocated and adopted for obtaining additional remuneration for the farmers. Medicinal and aromatic plant as if Rosemary (Rosmarinus officinalis L) is an aromatic perennial shrub by herb that belongs to the family Labiatae (Directorate Plant production, 2009). The dried leaf material and essential oil of rosemary are obtained from leaves and flowering twigs. The leaves are used as a culinary herb and essential oil is extensively used in food, Flavor and fragrance industries (Beemnet et al, 2013). Essential oil also used almost wholly in the perfumery industry forthe production of soaps, detergents, household spraysand other products (Joyteal, 2001).

Carrot (Daucus carota L.) is a widely grown root vegetable of the apiaceous family. Carrots have been one of the most important means used to mitigate vitamin A deficiency. Carrot roots are a rich source of carotenoids, precursors of vitamin A. Small holder's Farmers have limited land holding in the south region and the area highly populated therefore there is a need to improve land use system and the way to improve their income generation methods through intercropping of companion crops like carrot and rosemary.

Intercropping is the growing of two or more cultivars simultaneously in the same land by utilizing resources such as soil, water, nutrients and solar radiation more efficiently (Rana et al, 2013). This cropping system increased total productivity per unit land, per unit time and improves the judicious utilization of the land and other resources on farm (Anitha et al,2001). Enhancing agricultural 
production per unit area is the only way to increase agricultural production through more efficient use of natural resources with minimal impact on the environment in order to meet the growing population demands (Hobbs et al, 2008). Multiple cropping is one of the best ways of increasing production per unit area by growing two crops of dissimilar growth habit in the same field with little intercrop competition. Intercropping offers the possibility of yield advantage relative to sole cropping through yield stability and improved yield and thus providing diversified needs of small farmers, stability of yield over different seasons, better control of weeds, insect pests and diseases as well as control of soil erosion (Emam 2003).

Different researchers employed various measures of the efficiency of intercropping systems relative to sole cropping. A number of indices such as land equivalent ratio, area time equivalent ratio, relative crowding coefficient, competitive ratio, aggressivity, actual yield loss, monetary advantage, and intercropping advantage have been proposed to describe competition within and economic advantages of intercropping systems (Ghoshet al, 2004; Mazaheri et al, 2006; Yilmazet al,2007). Comparisons in competitive ability of the intercrop components were often made by calculating crowding coefficients and aggressivity values as in (Willey, 1991).Therefore, the present study carried out to investigate the competitiveness and yield advantage of carrot-rosemary intercropping over solitary using different competitive indices and to determine economical and environmentally suitable carrot-rosemary intercropping pattern.

\section{Material AND Method}

To investigate the competitiveness and yield advantage of carrot-rosemary intercropping over solitary a field study was conducted at Wondo Genet Agricultural Research center for two consecutive years on sandy clay loam with soil $\mathrm{pH}$ of 5.91, which was slightly acidic. Wondo Genet Agricultural Research Center is geographically located at $07^{\circ} 19.1^{\prime}$ North latitude, $38^{\circ} 30^{\prime}$ East longitude and an altitude of 1780 m.a.s.l.

The experimental design was randomized complete block design (RCBD) in additive series with three replications. Spacing between plots and replication were $1 \mathrm{~m}$ and $1.5 \mathrm{~m}$ respectively. The plot size was $8.64 \mathrm{~m} 2$ ( 3.6 width and $2.4 \mathrm{~m}$ length). Rosemary seedling was raised on the nursery for three months before transplanting to the actual field. Rosemary seedling was transplanted according to plant geometry of intercropping ratio in row additive series and simultaneously carrot seeds mixed with sand were directly sown inline row spacing of $25 \mathrm{~cm}$ by hand and covered lightly with soil. Seedlings of carrot were thinned to a plant-to-plant the distance of $5 \mathrm{~cm}$, soon after to established population density of the main crop. Recommended inorganic fertilizer $64 \mathrm{~N} \mathrm{~kg}$ ha-1 and $46 \mathrm{~kg}$ ha-1 P2O5 (TSP) for carrot was used. Rosemary harvesting was done at the nine-month interval after transplanting for two subsequent years.

Yield and yield components of the two crops collected based on the recommended harvesting seasons for each crop. Essential oil content and essential oil yield of rosemary were determined by taking $300 \mathrm{~g}$ of fresh leaves and stem composite samples harvested from three middle rows of a plot. Prevailing local market prices of carrot and rosemary were taken for economic analysis and the prices of carrot and Rosemary were 6 and 36.4 ETB/Ethiopian Birr), respectively, during the experiment. Finally, the collected data subjected to analysis of variance to test the significance of treatment effects using statistical analysis software 9.4 (SAS Institute Inc. 2014). The least significant difference (LSD) test was applied to differentiate the treatment differences at $\mathrm{P} \square 0.05$ probability level (Steel and Torrie1980). Pearson correlation coefficient and linear regression analysis were performed using statistical analysis software 9.4 (SAS, 2014).

The yield advantage of different intercropping systems over the mono-cropping of the individual crops were determined in terms of total yield equivalent, land equivalent ratio and land equivalent coefficient.

Land equivalent ratio (LER) which verifies the effectiveness of intercropping over sole cropping in using environmental resources.

$T L E R=P L E R$ carrot + PLER rosemary

$P L E R$ carrot $=Y I C / Y C$ 
PLER rosemary $=$ YIrose $/$ Yrose

Where TLER, total land equivalent ratio; PLER carrot, Partial land equivalent ratio of carrot; PLER rosemary, Partial land equivalent ratio of rosemary; YIO, carrot yield in intercropping system; YC, carrot yield in sole planted; YI rose, rosemary yield in intercropping system; Y rose, rosemary yield in sole planted.

Land Equivalent Coefficient (LEC) calculated using the following formula:-

$L E C=$ PLER carrot $*$ PLER rose

Competition functions: The competitive functions of the two crop computed in terms of relative crowding coefficient, aggressivity and competitive ratio.

\section{Relative crowding coefficient (RCC)}

As proposed by (Dewit 1960) relative crowding coefficient (K) measure the dominance of one species over the other in a mixture and can be calculated as follow: -

$K=K$ carrot $*$ K rose

Konion $=\frac{[Y I C * Z I \text { rose }]}{(Y C-Y I O) * Z I C}$

$K$ rose $=\frac{[\text { YIrose } * \text { ZIC }]}{(\text { Yrose }- \text { YIrose }) * \text { ZIrose }}$

Where $\mathrm{K}$, total relative crowding coefficient; K-carrot, relative crowding coefficient of carrot; Krose, relative crowding coefficient of rosemary; YIO, carrot yield in intercropping system; YC, carrot yield in sole planted; YI rose, rosemary yield in intercropping system; Y rose, rosemary yield in sole planted; ZI rose, proportion of rosemary in intercropping system; ZIC, proportion of carrot in intercropping system. When the value of $\mathrm{K}$ is greater than 1, there is a yield advantage; when $\mathrm{K}$ is equal to 1, there is no yield advantage; and, when it is less than 1.00, there is a disadvantage;

Aggressivity (A) used to determine the competitive relationship between the two crops in a mixture and calculated using the following formula:

$A O=\left\{\frac{Y I C}{Y C} * Z I C\right\}-\left\{\frac{\text { YIrose }}{\text { Yrose }} *\right.$ ZIrose $\}$
Arose $=\left\{\frac{\text { Irose }}{\text { Yrose }} *\right.$ ZIrose $\}-\left\{\frac{Y I C}{Y C} * Z I C\right\}$

Where AC, Aggressivity of carrot; Arose, Aggressivity of rosemary; YIC, carrot yield in intercropping system; YC, carrot yield in sole planted; YI rose, rosemary yield in intercropping system; Y rose, rosemary yield in sole planted; ZI rose, proportion of rosemary in intercropping system; ZIC, proportion of carrot in intercropping system.

Competitive ratio (CR):- The CR represents simply the ratio of individual LERs of the two component crops and takes into account the proportion of the crops on which they initially sown. We can determine using the following formula:

CRO $=\left(\frac{\text { LERcarrot }}{\text { LERrose }}\right) *\left(\frac{\text { ZIrose }}{\text { ZIC }}\right)$

CRrose $=\left(\frac{\text { LERrose }}{\text { LERcarrot }}\right) *\left(\frac{\text { ZIcarrot }}{\text { ZIrose }}\right)$

Where CRC, carrot competitive ratio; CRrose, rosemary competitive ratio; LER carrot, partial land equivalent ratio of carrot; LERrose, partial land equivalent ratio of rosemary; ZI rose, proportion of rosemary in intercropping system; ZIC, carrot proportion in intercropping system.

Actual yield loss (AYL) index, which gave more accurate information about the competition than the other indices between components of intercropping system. The AYL is the proportionate yield loss of intercrops compared to sole crop. 
$A Y L=A Y L$ carrot + AYLrose

$A Y$ Lcarrot $=\left\{\frac{\frac{Y I C}{Z I C}}{\frac{Y C}{Z C}}\right\}-1$

AYLrose $=\left\{\frac{\frac{\text { YIrose }}{\text { ZIrose }}}{\frac{\text { Yrose }}{\text { Zrose }}}\right\}-1$

Where AYL carrot, Actual yield loss of carrot; AYL rose, Actual yield loss of rosemary; YIC, carrot yield in intercropping system; YC, carrot yield in sole planted; YI rose, rosemary yield in intercropping system; Y rose, rosemary yield in sole planted; ZI rose, proportion of rosemary in intercropping system; ZIC, carrot portion in intercropping system.

Intercropping advantage (IA) was estimated as IA $=$ AYL $x$ Price of economic yield of carrot and essential oil yield of rosemary (the current price of yield of carrot and essential oil yield of rosemary are 13 and 20 Ethiopian Birr per $\mathrm{kg}$, respectively. Finally, the collected data were statistically analyzed using SAS computer software version 9.4 English and the significance difference between any two treatments means tested by least significant difference (LSD) at 5\% probability level.

\section{RESULT AND DISCUSSION}

The economic yield of carrot and rosemary are presented in table 1 . The cropping system significantly $(\mathrm{P}<0.05)$ influenced the economic yield of the carrot. Solely planted carrot gave the highest yield, which was statically at par with carrot intercropped with rosemary at $25 \%, 50 \%$ and $75 \%$ population density, respectively. Comparable research findings reported by (Nigussie et al, 2017; Kadali VG, et $a l, 1989)$ who reported that solely planted onion gave higher dry-bulb yield than that of intercropped yield. This result suggested that as population densities of the companion crops increased the yield of the main crop (carrot) decreased. The lowest yield obtained in carrot intercropped with rosemary at $100 \%$ population density. This might be associated with growth resources (light, water, nutrients and so on) competition by the companion crop. The finding of (Nigussie et al, 2017; Marey 2003; Talukder et al,2015) who reported that increased population density of the companion crop significantly affected the yield of the mail crop confirm these results. Carrot yield positively and significantly correlated with a partial land equivalent ratio of carrot $(\mathrm{r}=0.99)$ but negatively and significantly correlated with essential oil yield of rosemary, the partial land equivalent ratio of rosemary, total land equivalent ratio and land equivalent coefficient $(r=0.96, r=0.99, r=0.98$, and $\mathrm{r}=0.94)$, respectively (Table 4).

Similarly, the essential oil yield of rosemarywas significantly $(\mathrm{p}<0.05)$ influenced by cropping system; minimum (26.56 kg ha-1) and maximum (47.847 $\mathrm{kg} \mathrm{ha}^{-1}$ ) essential oil yield obtained from intercropped and sole planted rosemary, respectively. Regarding to the intercropping patter, the essential oil yield of rosemary significantly affected by different levels of the intercropping patterns. The maximum (45.71 kg ha-1) and minimum $\left(12.62 \mathrm{~kg} \mathrm{ha}^{-1}\right)$ essential oil yield recorded in treatments where carrot intercropped with rosemary at $100 \%$ and $20 \%$ population density, respectively. Unlike to that of main crop economic yield of the companion crop increased with population density. This possible due to the increment in above ground biomass as population density of the companion crop increased. Equivalent research finding witnessed on Onion-rosemary intercropping (Nigussie et al, 2017) and Rose-scented geranium intercropped with vegetables (Rajesh et al, 2011). The essential oil yield of rosemary positively and significantly correlated with a partial land equivalent ratio of rosemary, total land equivalent ratio and land equivalent coefficient ( $r=0.99, r=0.99$ and $r=0.99)$, respectively nevertheless negatively and significantly correlated with partial land equivalent ratio of carrot $(\mathrm{r}=0.96)$ (Table 4).

Pooled mean analysis result showed that, the partial land equivalent ratio of carrot not significantly $(\mathrm{P}<0.05)$ affected by different intercropping patterns. However, the highest the numerical value obtained while carrot intercropped with rosemary at $25 \%$ population density and its value decreased as the population density of the companion crop increased. Conversely, partial land the equivalent ratio of the companion crop (rosemary) was significantly $(\mathrm{P}<0.05)$ influenced by the intercropping 
pattern (Table 1); highest (0.96) and lowest (0.27) partial land equivalent ratio resulted in treatments where carrot intercropped with rosemary at $100 \%$ and $25 \%$ population density, respectively. Unlike, the carrot, partial land equivalent ratio of rosemary had shown increasing tends while population density increased. Similarly, (Nigussie et al, 2017; Mariga et.al. 2001), reported that a higher partial land equivalent ratio of the companion crop observed at higher population densities of onion in onionrosemary intercropping and pigeon pea in maize/ pigeon pea intercropping, respectively.

Table1. Yield and Essential oil yields, Land equivalent ratio and Land equivalent coefficient for sole stands and mixture of Carrot with Rosemary.

\begin{tabular}{|l|l|l|l|l|l|l|}
\hline \multirow{2}{*}{ Treatments } & \multicolumn{2}{l|}{$\begin{array}{l}\text { Yield and Essential oil } \\
\text { yield (Kg/ha) }\end{array}$} & $\begin{array}{l}\text { Land Equivalent ratio } \\
\text { (LER) }\end{array}$ \\
\cline { 2 - 7 } & Carrot & Rosemary & $\begin{array}{l}\text { PLER- } \\
\text { carrot } \\
\end{array}$ & & $\begin{array}{l}\text { PLER- } \\
\text { Eosemary } \\
\text { Equivalent } \\
\text { coefficient } \\
\text { LEC }\end{array}$ & TLER \\
\hline Sole carrot & $32.72^{\mathrm{a}}$ & - & - & - & - & - \\
\hline Sole rosemary & - & $47.85^{\mathrm{a}}$ & - & - & - & - \\
\hline 100 carrot:25\%rosemary & $29.33^{\mathrm{ab}}$ & $12.62^{\mathrm{c}}$ & 0.91 & $0.27^{\mathrm{c}}$ & $1.18^{\mathrm{b}}$ & $0.25^{\mathrm{b}}$ \\
\hline 100 carrot:50\%rosemary & $27.77^{\mathrm{ab}}$ & $23.44^{\mathrm{b}}$ & 0.87 & $0.49^{\mathrm{b}}$ & $1.36^{\mathrm{b}}$ & $0.39^{\mathrm{b}}$ \\
\hline 100 carrot:75\%rosemary & $26.93^{\mathrm{ab}}$ & $24.48^{\mathrm{b}}$ & 0.83 & $0.59^{\mathrm{b}}$ & $1.42^{\mathrm{b}}$ & $0.41^{\mathrm{b}}$ \\
\hline 100 carrot:100\%rosemary & $25.23 \mathrm{~b}$ & $45.71^{\mathrm{a}}$ & 0.77 & $0.96^{\mathrm{a}}$ & $1.73^{\mathrm{a}}$ & $0.84^{\mathrm{a}}$ \\
\hline LSD & 6.91 & 6.15 & $0.21 \mathrm{~ns}$ & 0.15 & 0.28 & 0.28 \\
\hline CV \% & 12.92 & 10.59 & 12.34 & 13.16 & 9.92 & 29.87 \\
\hline
\end{tabular}

Means in a column followed by the same letter(s) are not significantly different at $5 \%$ level of probability using least significant difference. $N S=$ Not Significant

All intercropping patters had higher LER than monoculture, which indicated the superiority of intercropping over monoculture. The highest amount of LER 1.73 obtained in treatment where carrot intercropped with rosemary at $100 \%$ population density (Table 1). This result indicated that monocropping would require 0.73 more units of land to have the same yield as intercropped. The yield advantage might be due to the efficient utilization of growth resources by the intercropped crop over mono cropped (Willey, 1979; Reddy, 2000). This implies that the association of carrot and rosemary at this intercropping pattern is complementary to each other on growth resource utilization. Carrot and radish intercropping in raw culture after rice harvesting has 1.66-2.15 LER (Amoli, 2003).Similar research findings also reported by (Abdul et al,2009; Nigussie et al. 2016; Nigussie et al, 2017; Nigussie et al, 2019; Ramkatet al, 2008; Takim 2012). The total land equivalent ratio positively and significantly correlated with a land equivalent coefficient ( $\mathrm{r}=0.98)$ (Table 4).

According to (Adetiloye et al, 1983), for a two-crop mixture, the minimum expected productivity coefficient should be $25 \%$; meaning a yield advantage if the land equivalent coefficient (LEC) value exceeded 0.25 . Except, carrot intercropped with rosemary at $25 \%$ population density the value of LEC was greater than the critical value 0.25 and the maximum value $(0.84)$ was obtained in treatment where carrot intercropped with rosemary at $100 \%$ population density (Table 1). (Similarly, Egbe 2005; Nigussie et al, 2017;Nigussie et al,2019) has reported LEC values greater than the critical in intercropping of onion-rosemary and sorghum-soybean at different spatial arrangements, respectively.

\section{Relative Crowding Coefficient (RCC)}

Except, carrot intercropped with rosemary at $25 \%$ population density relative crowding coefficient of carrot greater than one indicating making intercropping at this intercropping patter is disadvantageous. However, the relative crowding coefficients of rosemary was greater that unit in all intercropping pattern; this showed that making intercropping of rosemary had a benefit in terms of competition. Moreover, the relative crowding coefficients of rosemary had had increasing trends while its population density increased, the highest (2.94) and lowest (1.28) RCC values of rosemary were obtained in carrot intercropped with rosemary at $100 \%$ and $25 \%$ population density, respectively (Table 2). Similar to K- of carrot, the product of relative crowding coefficient of the two-component crops was less than one in carrot intercropped with rosemary at $25 \%$ population density, this revealed that making intercropping was no yield advantage of one crop over another and the system had a disadvantage. However, the maximum relative crowding coefficient of the two-component crops was obtained in carrot intercropped with rosemary at $100 \%$ population density; this result indicated that 
adopting this cropping patter had an advantage over the others. Our result in agreement with the finding of (Nigussie et al, 2017; Nigussie et al,2019) who reported the maximum relative crowding coefficient of the two component crops obtained at onion intercropped with $80 \%$ rosemary population density.

Table2. Effects of intercropping pattern on Relative crowding coefficient, Aggressivity and Competitive Ratio in Carrot-Rosemary intercropping system.

\begin{tabular}{|c|c|c|c|c|c|c|c|}
\hline \multirow[t]{2}{*}{ Treatments } & \multicolumn{3}{|c|}{$\begin{array}{l}\text { Relative crowding coefficient } \\
\text { (K) }\end{array}$} & \multicolumn{2}{|c|}{$\begin{array}{l}\text { Aggressivity } \\
\text { (A) }\end{array}$} & \multicolumn{2}{|c|}{$\begin{array}{l}\text { Competitive Ratio } \\
\text { (CR) }\end{array}$} \\
\hline & Carrot & Rosemary & Total & Carrot & Rosemary & Carrot & Rosemary \\
\hline 100 carrot: $25 \%$ rosemary & -0.82 & 1.28 & $-2.12^{b}$ & $84.33^{\mathrm{a}}$ & $-84.33 c$ & $0.25^{\mathrm{a}}$ & $0.79^{b}$ \\
\hline 100 carrot:50\%rosemary & 1.56 & 1.48 & $3.04^{b}$ & $55.80^{\mathrm{b}}$ & $-55.80^{b}$ & $-2.27^{\mathrm{a}}$ & $1.16^{\mathrm{ab}}$ \\
\hline 100 carrot: $75 \%$ rosemary & 1.71 & 2.11 & $3.66^{\mathrm{b}}$ & $51.03^{\mathrm{b}}$ & $-51.03^{b}$ & $-2.30^{\mathrm{a}}$ & $1.17^{\mathrm{ab}}$ \\
\hline 100 carrot: $100 \%$ rosemary & 2.39 & 2.94 & $31.17^{\mathrm{a}}$ & $-8.65^{c}$ & $8.65^{\mathrm{a}}$ & $-9.33^{\mathrm{b}}$ & $1.33^{\mathrm{a}}$ \\
\hline
\end{tabular}

Means in a column followed by the same letter(s) are not significantly different at $5 \%$ level of probability using least significant difference. $N S=$ Not Significant

\section{Aggressivity}

The analyzed data are shown in Table 2 revealed that the component crops did not compete equally. Except, carrot intercropped with rosemary at $100 \%$ population density the whole intercrop pattern specified both dominated behavior as indicated by their negative (-) sign for rosemary crop and dominant performance observed on carrot crop as designated by their positive (+) sign. Aggressivity values of carrot was decreased as the population density of the companion crop increased; the highest aggressivity value (+84.33) of carrot was found in treatment where carrot intercropped with rosemary at $25 \%$ population density closely followed by $50 \%$ rosemary $(+55.8)$. On the other hand, the lowest value $(-8.65)$ obtained from carrot intercropped with rosemary at $100 \%$ population density; indicated that carrot was the least competitive crop at $100 \%$ rosemary population density. This result in agreement with those research findings obtained by (Abou-Elela and Gadallah (2012); Nigussie et al,2016; Nigussie et al, 2017; Nigussie et al, 2019). Unlike carrot, the aggressivity value of rosemary increased as its population density increased, which means as its population density increased seemingly aggressivity also increased. The maximum and minimum aggressivity values of rosemary obtained at $100 \%$ and $25 \%$ population densities of rosemary, respectively.

\section{Competitive ratio $(\mathrm{CR})$}

The analyzed result showed that intercropped carrot had a lower competitive ratio in all mixtures as compared with rosemary. The highest $(0.25)$ and the lowest $(-9.33) \mathrm{CR}$ values of carrot obtained in treatment where carrot intercropped with rosemary at $25 \%$ and $100 \%$ population density, respectively and decreased gradually as the proportion of the companion crop in the mixture increases. Similar research finding reported by (Nigussie et al,2019) who indicated that onion competitive ratio decreased as the population density of rosemary increased from 25-100\%. Conversely, the CR values for rosemary increased with an increase in its aggressivity and population density in the mixtures (Table 2). Among the different rosemary population densities intercropped with carrot, the rosemary proved to be better competitive when grown in $100 \%$ population density.

\section{Actual Yield Loss}

The actual yield loss (AYL) tells us the proportionate yield loss due to intercropping compared to sole crop. Likewise, partial actual yield loss represents the proportionate yield loss of each specie grown as intercrops compared to pure stand. Positive or negative values of AYL indicated the advantage or disadvantage of the intercropping when the main aim is to compare the yield on a per plant basis (Banik et al, 2000). In this study, actual yield loss of carrot had negative values in treatments; maximum (23\%) and minimum (9\%) yield loss of carrot were recorded at carrot intercropped with rosemary at $50 \%$ and $25 \%$ population density, respectively.

However, the actual yield loss of rosemary had shown both positive and negative values; the positive values were observed in treatments where carrot intercropped with rosemary at $50 \%$ and $25 \%$ population density indicating a yield gain of $2 \%$ and $7 \%$, respectively, compared to sole rosemary 
yield. Data pertaining to total yield loss, analysis of variance depicted that total yield loss significantly influenced by different intercropping patterns. In all treatments negative values of total yield loss observed; this point out making an intercropping had a disadvantage over monoculture. However, numerically the lowest yield loss observed in treatment where carrot intercropped with rosemary at $25 \%$ population density (Table 3 ).

Table3. Effects of intercropping pattern on Actual Yield Loss and Intercropping Advantage in CarrotRosemary intercropping system.

\begin{tabular}{|l|l|l|l|l|l|l|}
\hline \multirow{2}{*}{ Treatments } & \multicolumn{3}{|l|}{ Actual Yield Loss (AYL) } & \multicolumn{3}{l|}{ Intercropping Advantage (IA) } \\
\cline { 2 - 7 } & Carrot & Rosemary & Total & Carrot & Rosemary & Total \\
\hline 100 carrot: $25 \%$ rosemary & -0.09 & $0.07^{\mathrm{a}}$ & $-0.02^{\mathrm{a}}$ & $-1.08 \mathrm{a}$ & $1.33^{\mathrm{a}}$ & $0.25^{\mathrm{a}}$ \\
\hline 100 carrot:50\%rosemary & -0.23 & $0.02^{\mathrm{a}}$ & $-0.21^{\mathrm{ab}}$ & $-2.75 \mathrm{a}$ & $0.49^{\mathrm{a}}$ & $-2.27^{\mathrm{a}}$ \\
\hline 100 carrot:75\%rosemary & -0.20 & $-0.35^{\mathrm{b}}$ & $-0.55^{\mathrm{b}}$ & $-2.36 \mathrm{a}$ & $-6.97^{\mathrm{b}}$ & $-9.33^{\mathrm{b}}$ \\
\hline 100 carrot:100\%rosemary & -0.13 & $-0.04^{\mathrm{a}}$ & $-0.16^{\mathrm{ab}}$ & $-1.51 \mathrm{a}$ & $-0.79^{\mathrm{a}}$ & $-2.30^{\mathrm{a}}$ \\
\hline
\end{tabular}

Means in a column followed by the same letter(s) are not significantly different at $5 \%$ level of probability using least significant difference. $N S=$ Not Significant

\section{Intercropping Advantage}

Intercropping advantage expressing the advantage or disadvantage of intercropping over solitary related to economic feasibility as stated by (Banik et al. 2000). The highest the intercropping advantage obtained in treatment where carrot intercropped with rosemary at $25 \%$ population density. However, the lowest $(-9.33,-2.30$ and -2.27$)$ intercropping advantage was recorded in treatment where carrot intercropped with rosemary at 75, 100 and $50 \%$ population densities, respectively this signifying making an intercropping of rosemary at this population density leads to a maximum yield loss of carrot. Our result fully supported by (Nigussie et al,2019) reported that maximum intercropping advantage obtained from less populated companion crop intercropped with the main crop.

Table4. Correlation coefficient among economic yield, land equivalent ratio and land equivalent coefficient

\begin{tabular}{|l|l|l|l|l|l|l|}
\hline Treatments & Carrot yield & $\begin{array}{l}\text { Essential oil } \\
\text { yield }\end{array}$ & $\begin{array}{l}\text { PLER of } \\
\text { carrot }\end{array}$ & PLER rose & TLER & LER \\
\hline Carrot yield & 1 & $-0.967^{*}$ & $0.99 * *$ & $-0.99^{* *}$ & $-0.99^{*}$ & $-0.94 \mathrm{~ns}$ \\
\hline Essential oil yield & & 1 & $-0.96^{*}$ & $0.99^{* *}$ & $0.99^{* *}$ & $0.99^{* *}$ \\
\hline PLER of carrot & & & 1 & $-0.99^{* *}$ & $-0.98^{* *}$ & $-0.94 \mathrm{~ns}$ \\
\hline PLER rose & & & & 1 & $0.99^{* * *}$ & $0.98^{*}$ \\
\hline TLER & & & & & 1 & $0.98^{*}$ \\
\hline LER & & & & & & 1 \\
\hline
\end{tabular}

\section{CONCLUSION AND RECOMMENDATION}

The previously mentioned result revealed that intercropping carrot with rosemary in different intercropping patterns might affect the economic yields due to competition between the two crops compared to solitary. The highest carrot and rosemary economic yield was recorded at solitary cropping than that of intercropped.The values of $\mathrm{K}$, A, and CR clearly indicated that different cropping patterns significantly influenced the competitive ability of the main and companion crops. In one hand, the highest value of LER (1.73), LEC (0.84) and K (31.17) obtained when carrot intercropped with rosemary at $100 \%$ rosemary population density. On the other hand, less actual yield loss and better intercropping advantage observed in treatment where carrot intercropped with rosemary at $25 \%$ population density. Therefore, this research finding suggested that intercropping of carrot with rosemary at $100 \%$ population density enhanced yield advantage and Competitiveness as indicated by higher LER and relative crowding coefficients (K). Conversely, the result also illustrated that intercropping carrot with rosemary at $25 \%$ population density revealed less actual yield loss and maximum intercropping advantage.

\section{REFERENCES}

[1] Directorate Plant Production. Production Guidelines for Rosemary, Agriculture, Forestry and Fisheries, Republic of South Africa, 26 pp. (2009).

[2] Beemnet, M., Basazenew, D., and Desta, F., Variability in Ethiopian Rosemary (Rosmarinus officinalis L.) Collections for Agronomic and Chemical Traits. Fourth Biennial Conference of the Ethiopian Horticultural 
Science Society on Sustainable Training, Research, and Development towards Achieving the Growth and Transformation Plan (GTP). April 12-13. Ambo University, Ambo, Ethiopia. (2013).

[3] Joy, P.P., Thomas J, Mathew S., Jose G., Joseph J. Aromatic plants in: Bose TK, Kabir J, Das P, Joy PP (Eds) Tropical Horticulture (Vol II), Naya Prokash, Calcutta, pp 633-733. (2001).

[4] Rana, M. M., Bhuiya, M. S. U., and Akhand, M. I. M., Effect of intercropping of sesbania rostrata with transplant a man rice on yield and profitability. IOSR J. Agri. Veter. Sci., 2(1), 10-14. (2013).

[5] Anitha, S., Geethakumari, V. L. and Raghavan Filial, G., Effect of intercrops on nutrient uptake and productivity of chili-based cropping system. Journal of Tropical Agriculture 39:60 61. (2001)

[6] Hobbs, P.R., Sayre K., Gupta R., The role of conservation agriculture in sustainable agriculture. Philos. Trans. R. Soc. B., 363: 543-555 (2008).

[7] Emam, Y. Cereal Production, Tehran University Press, Iran. (In Persian) (2003).

[8] Ghosh, P.K., Growth, yield, competition and economic of groundnut / cereal fodder intercropping systems in the semi-arid tropics of India. Field Crops Res. 88: 217-237. (2004).

[9] Mazaheri, D., Ahad M., Meysan O., Assessing the land equivalent ratio of two corn varieties intercropping at various nitrogen levels in Karaj, Iran. J. Central Eur. Agric.; 7(2): 359-364(2006).

[10] Yilmaz S, Atak M., Erayman M. Identification of advantages of maize-legume intercropping over solitary cropping through competition indices in the East Mediterranean Region. Turkey J. Agric. 16: 217-228(2007). [11] Willey, R.W., Evaluation and Presentation of Intercropping Advantages. Experimental Agriculture, 21:119123 (1991).

[12] SAS Institute Inc., (2013) Base SAS® 9.4 procedures guide. SAS Institute Inc., Cary, NC, USA(2013).

[13] Steel, R.G.D., and Torrie, J.H., Principles and Procedures of Statistics: a Biometrical Approach. 2nd Edition. McGraw-Hill. New York. 631pp. (1980).

[14] De Wit C.T., On Competition. Verslagen Land bouwkundige Onderzoekigen, 66, 1-82(1960).

[15] Nigussie, A., Lulie, B., Chala, M., Intercropping of Onion with Rosemary as Supplementary Income Generation at Wondo Genet Sidama zone, Southern Ethiopia. Acad. Res. J. Agri. Sci. Res. 5(2): 107-115(2017).

[16] Kadali V.G., Banakapur V.M., Patil A.A., Studies on companion cropping of onion with chilli and French bean. J. Maharashtra Agril. Univ. 14:378-379 (1989)

[17] Marey, R.A., Effect of intercropping of faba bean of chickpea on sugar beet. Ph.D. Thesis, Faculty of Agriculture -Assuit University, Egypt. (2003).

[18] Talukder, J. M., Rahman, M. Biswas and Asaduzzaman M., Optimum Ratio of Coriander Intercropping with Onion. International Journal of Plant \& Soil science, 4(4): $404-410$ (2015).

[19] Rajesh, K.V., Ram, S.V., Amit, C., Anand, S.,Laiq-ur, R., and Alok, K. Biomass yield, essential oil yield and essential oil composition of rose- scented Geranium (Pelargonium graveolens L) intercropped with vegetables. Intern J. Agric Res 6(12):830-839 (2011).

[20] Mariga, I. and Chivinge O., Effects of maize density, bean cultivar and bean spatial arrangement on intercrop performance. African Crop Science Journal. 9 (3) 487-497 (2001).

[21] Willey, R.W., Intercropping-its importance and research needs. Competition and yield advantages. Field Crops Abstr., 32:1-10(1979a).

[22] Reddy, R.S., Principles of Crop Production. Kalyani Publishers, New Delhi-110002, India. (2000).

[23] Amoli, N., An investigation to compare the intercropping of carrot and radish in different row spacing in low land. Abstract book of the 3rd Iran congress of Horticultural science. Karaj. Iran. PP.311.( 2003).

[24] Abdul, J., Riaz, A., I. H., Bhatti., Zaheer A. V., Wasi-u-Din and M.M. Khan. Assessment of yield advantages, competitiveness and economic benefits of Diversified direct-seeded upland rice-based intercropping systems under strip geometry of planting. Pak. J. Agri. Sci., Vol. 46(2) (2009).

[25] Nigussie, A., Advantages of Maize-Haricot bean Intercropping over Sole Cropping through Competition Indices at west Badewacho woreda, Hadiya Zone, SNNPR. Acad. Res. J. Agri. Sci. Res. 4(1): 1-8(2016).

[26] Nigussie, A., Estimation of Yield Advantage and Competitiveness of Onion-Rosemary Intercropping Over Sole Cropping at Wondo Genet, Southern Ethiopia. Academic Journal of Plant Sciences 12 (3): 52-60 (2019). 
[27] Ramket, R.C., Wangai A.W., Ouma, J.P., Rapando P.N., \& Lelgut D.K., Cropping system influences tomato spotted wilt virus disease development, trips population and yield of tomato (Lycopersicon esculentum). Annals of Applied Biology, 153:373-380 (2008).

[28] Takim, F. O. Advantages of Maize-Cowpea Intercropping over Sole Cropping through Competition Indices. J. Agri. Biodiversity Res. Vol. 1, Issue 4, pp. 53-59( 2012).

[29] Adetiloye, P.O., Ezedinma F.O.C., Okigbo, B.N. A., land coefficient concept for evaluation of competitive and productive interactions on simple complex mixtures. Ecological Modelling, 19: 27-39(1983).

[30] Egbe, O.M., Evaluation of agronomic potentials of some pigeon pea genotypes for intercropping with maize and sorghum in Southern Guinea Savanna (2005).

[31] Abou-Elela, A.M. and Gadallah, R.A., Effect of transplanted seedling age of intercropped fodder beet with faba bean and nitrogen fertilizer levels on yield and it's component of fodder beet and faba bean. Zagazig J. Agric. Res., 39 (6): 1057 -1067 (2012).

[32] Banik, P., Sasmal, P., Ghosal, K., Bagchi, D.K., Evaluation of mustard (Brassica campestris var. Toris) and legume intercropping under 1:1 and 2:1 row-replacement series system. J. Agro. Crop Sci. 185: 9-14(2000).

Citation: AshenafiNigussie, et.al.,, "Competitiveness and Yield Advantage of Carrot-Rosemary Intercropping over Solitary at Wondo Genet, Southern Ethiopia” International Journal of Research Studies in Agricultural Sciences (IJRSAS), 2020; 6(8), pp. 1-9, https://doi.org/10.20431/2454-6224.0608001

Copyright: (C) 2020 Authors. This is an open-access article distributed under the terms of the Creative Commons Attribution License, which permits unrestricted use, distribution, and reproduction in any medium, provided the original author and source are credited. 